Himalayan Biodiversity 5: 38-44, 2017

ISSN :2382-5200

\title{
SYNERGISTIC EFFECTS OF ARTEMISIA VULGARIS, OCIMUM TENUIFLORUM, AZADIRACHTA INDICA AND CASTANOPSIS INDICA EXTRACTS AGAINST METHICILLIN-RESISTANT STAPHYLOCOCCUS AUREUS
}

\author{
Jyoti Chhetri', Krishna Gurung ${ }^{1,3}$, Abhisek Khadka², Reeju Sharma', Mira Kumari Khatri', \\ Anil Bhujel ${ }^{1}$, Amrita Acharaya ${ }^{1}$ and Goma Pokherel ${ }^{1}$ \\ ${ }^{1}$ Department of Microbiology, Pokhara Bigyan Tatha Prabidhi Campus, Pokhara, Nepal \\ ${ }^{2}$ Livelihood Officer, Rural Reconstruction Nepal. \\ ${ }^{3}$ Department of Microbiology, Prithivi Narayan Campus, Pokhara, Nepal. \\ chhetrijyo@gmail.com
}

\begin{abstract}
Staphylococcus aureus is a major public health concern. Methicillin resistant Staphylococcus aureus is not only resistant to methicillin and other $\beta$-lactam antibacterial agents but also to other antibacterial agents. Therefore, new agents are needed to treat Methicillin Resistant Staphylococcus aureus (MRSA). The main aim of the present research was to study the antibacterial activity of four plants extract against clinical isolates of Staphylococcus aureus at the purpose of overcoming its infection. The current investigation was carried out at Pokhara Bigyan tatha Prabidhi Campus based on the evaluation of traditional plants on its antibacterial activity against MRSA. Antibacterial activity of the medicinal plant extract was observed by mixing $100 \mathrm{~g}$ powder of collected leaves in $70 \%$ methanol making $1000 \mathrm{sml}$. After performed processes, extract was filtered and methanol was evaporated. Antibacterial activity of the medicinal plant extract was determined using agar well diffusion assay method. Methanol leaf extracts may have the potential to act against MRSA and could be a possible source to obtain new and effective herbal medicines to treat infections caused by methicillin resistant strains of microorganisms from community as well as hospital settings. The synergistic effect was clearly observed among all four medicinal herbs.
\end{abstract}

Key words: Azadirachta indica, Castanopsis indica, MRSA, Ocimum tenuiflorum, plant extract.

\section{INTRODUCTION}

Staphylococcus aureus can cause substantial morbidity and mortality. It is a major public health concern. It can adapt rapidly to the selective pressure of antibiotics and this has resulted in the emergence and spread of Methicillin resistant $S$. aureus which poses a serious public health (Kayastha 2010). Strains of $S$. aureus resistant to a large group of $\beta$-lactam antibiotics which includes the penicillins and cephalosporins are known as Methicillin Resistant Staphylococcus aureus (MRSA) (Joshi and Devkota 2014). MRSA causes more than $50 \%$ of hospital acquired infections (HAIs) and are more virulent than the methicillin sensitive strains (Sanjana et al 2010).

In the last few years, there has been great scientific interest in chemical and pharmacological investigations of the biological properties of medicinal plants. The use of extracts as antimicrobial agents shows a low risk of increasing resistance to their action, because they are complex mixtures, making microbial 
adaptability very difficult and it is also reported to have minimal side effects (Abd El-Kalek and Mohamed 2012).

Medicinal plants are abundant source of antimicrobial molecules. A wide range of medicinal plants extracts are used to treat several infections as they have potential antimicrobial activity (Javid et al 2015). Plants are rich in a wide variety of secondary metabolites, such as tannins, terpenoids, alkaloids, and flavonoids, which have been found in vitro to have antimicrobial, anti-viral, anti-parasites and anticancers properties (Geetha and Roy 2013). Ability of using most of the medicinal plants for the treatments for various diseases may lie in the antioxidant and antimicrobial effect of phytochemicals (Rathnayaka 2013). Some of the species that emerged from such an inventory are Artemisia vulgaris, Ocimum tenuiflorum, Azadirachta indica, Castanopsis indica (Bhatt et al 2012).

Azadirachta indica (Neem, Family- Meliaceae) is used in traditional medicine as a source of many therapeutic agents. Earlier studies on neem have showed that it contains active substances with multiple medicinal properties. Aqueous extract of neem leaf extract has a good therapeutic potential as anti-hyperglycemic agent and anti-inflammatory effect. Neem leaves has antibacterial properties and could be used for controlling bacterial contamination in the residential premise. The great potential of neem aqueous extract is a powerful chemotherapeutic agent (Maragathavalli et al 2012).

Artemisia vulgaris, family Compositae or Asteraceae commonly called Mugwort pollen. Its leaves have an antibacterial action, inhibiting S. aureus (Ashok and Upadhyaya 2010). Artemisia vulgaris is tolerant to most herbicides, while cultivation and mowing are not effective means of control and is commonly found along road sides (Barney and Di Tommaro 2003). This herb has been used worldwide in folk medicine since ancient time. They have been used as tonics, anti-malarial, anti-helminthic and antidiabetic, and in treating wounds, bronchitis, ulcers and tuberculos is intraditional Anatolian medicine (Erel et al 2012).

Ocimum sanctum belongs to the family Lamiaceae and is used as an important component for the ayuevedic treatment of various diseases and also possesses several pharmological properties such as antifertility, anticancer, antidiabetic and antimicrobial (AlAli et al 2014). Ocimum sanctum L., known as Krishna'Tulsi' in Hindi and 'Holy Basil' in English, is an erect softly hair aromatic herb or under shrub (Bhatt et al 2012). It is one of the holiest and most sacred herb grown widely in Nepal and India (Gupta et al 2013).

Castanopsis indica, family Fagaceae known as'Dhalne katus'and'Indian Chest nut'found throughout the Himalayan region of North East India, Bangladesh, Loas, Myanmar, Nepal, Sikkim, Bhutan, Thailand, Vietnam. A decoction of the leaves applied to treat stomach disorder and skin diseases (Dolai et al 2012). The leaf extract possesses a pronounced invitro antibacterial effect (Zivkovic et al 2009).

\section{MATERIALS AND METHODS}

\section{Study sites}

The study was conducted in Microbiology laboratory of Pokhara Bigyan Tatha Prabidhi Campus (PBPC) Pokhara, Nepal. Different MRSA strains collected from Microbiology Laboratory of Manipal Teaching Hospital, Pokhara were processed to observe synergistic effects of 4 medicinal herbs. Only leaves of the plants and Staphylococcus aureus resistant to Cefoxitin antibiotic were included in this study. 


\section{Laboratory analysis}

\section{Extraction of active component:}

Plant leaves were rinsed with tap water and then dried in shade. After shade drying, leaves were pulverized using domestic blender to powder form. Powdered material $(100 \mathrm{~g})$ was mixed with $1 \mathrm{~L}$ of $70 \%$ methanol and kept for 7 days in a closed glass bottles at room temperature. After 7 days, mixture was placed inside the safety cabinet which was cleaned with disinfectant and the continuous UV light was passed for 24 hours in a safety cabinet. Then, the mixture was filtered through Whatman filter paper. The water bath was adjusted to $65^{\circ} \mathrm{C}$. The extract produced was kept in a water bath which was kept inside a safety cabinet for 3 days for the complete methanol evaporation (Al-Ali 2014).

\section{Antimicrobial susceptibility testing by agar well diffusion method:}

The antibiotic sensitivity profiles of MRSA isolates were determined according to agar well diffusion method. A loopfull strain was inoculated in nutrient broth and incubated at $37^{\circ} \mathrm{C}$ for 4 hours. The mixture was then compared with 0.5 Mc Farland turbidity standard. Lawn culture of the test organism was made on the Muller Hinton agar plates using sterile cotton swab and the plates were dried for 15 minutes. A sterile cork borer was then used to make wells (6mm diameter). The extract in different volumes $(1 \mu \mathrm{L}, 25 \mu \mathrm{L}$, $50 \mu \mathrm{L}, 75 \mu \mathrm{L}$ and $100 \mu \mathrm{L})$ of different plants was placed on the wells. The culture plates were allowed to stand on the working bench for 30 minutes of pre-diffusion and were then incubated at $37^{\circ} \mathrm{C}$ for 24 hours. After $24 \mathrm{hrs}$, antibacterial activity was determined by measurement of diameter of zones of inhibition ( $\mathrm{mm}$ ).

\section{Synergistic method:}

The synergistic effect was observed with equal volume combination of:

Ocimum tenuiflorum + Castanopsis indica

Ocimum tenuiflorum + Artemisia vulgaris

Ocimum tenuiflorum +Azadirachta indica Castanopsis indica + Artemisia vulgaris

Castanopsis indica + Azadirachta indica Artemisia vulgaris + Azadirachta indica. All the experimental results were analyzed by two way ANOVA in Microsoft Excel.

\section{RESULT}

Four medicinal plants (Azadirachta indica, Artemisia vulgaris, Ocimum tenuiflorum and Castanopsis indica) methanol extracts were taken and their antimicrobial activities were studied and analyzed in combination form.

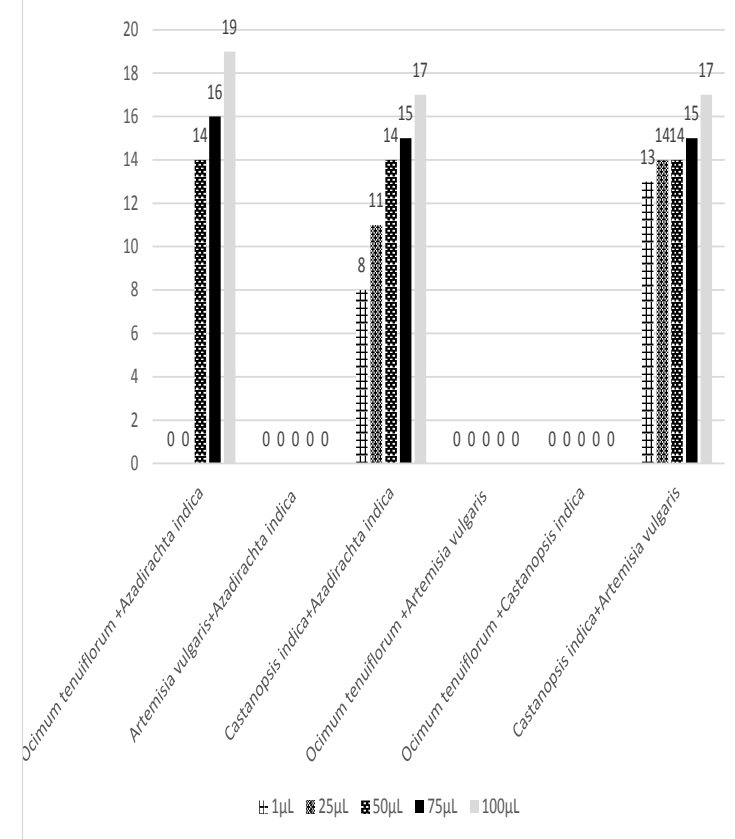

Figure 1: Zone of inhibition (in $\mathrm{mm}$ ) for different volume of leaf extracts against MRSA isolate number 1 .

The methanolic extract of leaves against MRSA isolates showed variable zone of inhibition. As shown in figure (1), in the lowest volume $(1 \mu \mathrm{L})$ 
$13 \mathrm{~mm}$ inhibition zone was given by Artemisia vulgaris + Castanopsis indica. For isolate number 1 Ocimum tenuiflorum + Castanopsis indica, Ocimum tenuiflorum +Artemisia vulgaris and Artemisia vulgaris + Azadirachta indica has $\mathrm{p}$ value greater than 0.05 ( $\mathrm{p}>0.05)$. But Castanopsis indica + Azadirachta indica has significantly different effect than others $(\mathrm{p}<0.05)$.

Table1: zone of inhibition (in $\mathrm{mm}$ ) for different volume of leaf extract against isolate number 2 .

\begin{tabular}{|c|c|c|c|c|c|c|}
\hline \multirow{2}{*}{$\begin{array}{c}\text { Isolate } \\
\text { no. }\end{array}$} & \multirow{2}{*}{$\begin{array}{l}\text { Medicinal } \\
\text { plant }\end{array}$} & \multicolumn{5}{|c|}{ Volume $(\mu \mathrm{L})$} \\
\hline & & 1 & 25 & $\mathbf{5 0}$ & 75 & 100 \\
\hline \multirow{6}{*}{$\begin{array}{c}\text { MRSA } \\
2\end{array}$} & $\begin{array}{c}\text { Ocimum } \\
\text { tenuiflorum } \\
+ \text { Azadirachta } \\
\text { indica }\end{array}$ & 0 & 9 & 11 & 13 & 16 \\
\hline & $\begin{array}{c}\text { Artemisia } \\
\text { vulgaris }+ \\
\text { Azadirachta } \\
\text { indica }\end{array}$ & 0 & 0 & 10 & 13 & 14 \\
\hline & $\begin{array}{c}\text { Castanopsis } \\
\text { indica+ } \\
\text { Azadirachta } \\
\text { indica }\end{array}$ & 0 & 10 & 12 & 14 & 16 \\
\hline & $\begin{array}{c}\text { Castanopsis } \\
\text { indica+ } \\
\text { Artemisia } \\
\text { vulgaris }\end{array}$ & 0 & 0 & 0 & 0 & 16 \\
\hline & $\begin{array}{c}\text { Ocimum } \\
\text { tenuiflorum } \\
+ \text { Castanopsis } \\
\text { indica }\end{array}$ & 0 & 0 & 0 & 0 & 14 \\
\hline & $\begin{array}{c}\text { Ocimum } \\
\text { tenuiflorum } \\
+ \text { Artemisia } \\
\text { vulgaris }\end{array}$ & 0 & 11 & 12 & 14 & 16 \\
\hline \multicolumn{2}{|c|}{ Mean total } & 0 & 5 & 7.5 & 9 & $\begin{array}{l}15 . \\
33\end{array}$ \\
\hline
\end{tabular}

As shown in table 2, at lowest volume, the antibacterial activity against isolate 2 showed resistances to all plants extracts but highest zone of inhibition was shown at $100 \mu \mathrm{L}$.

The zone of clearance was insignificant $(\mathrm{p}>0.05)$ for $O$. tenuiflorum $+C$. indica, $O$. tenuiflorum
+ A. vulgaris, O. tenuiflorum $+A$. indica and $C$. indica $+A$. vulgaris. The zone of inhibition were significant for $C$. indica $+A$. indica and $A$. vulgaris $+\quad$ A. indica $(\mathrm{p}<0.05)$.

In MRSA isolates no. 3, 4 and 5 all plant extracts showed resistance to $1 \mu L$ (i.e $0 \mathrm{~mm}$ ) but highest zone of inhibition to $100 \mu \mathrm{L}$.

In MRSA isolate no. 3 p-value found to be $>0.05$ for Ocimum tenuiflorum + Azadirachta indica, Castanopsis indica + Artemisia vulgaris and Ocimum tenuiflorum + Castanopsis indica. Significantly different character was given by Castanopsis indica + Azadirachta indica $(\mathrm{p}<0.05)$.

For isolate no. 4 the zone of clearance was significantly same $\mathrm{p}>0.05$ for $O$. tenuiflorum + $A$. indica, $C$. indica $+A$. vulgaris, $O$. tenuiflorum $+A$. vulgaris and $A$. vulgaris $+A$. indica and the zone of clearance was significantly different for $O$. tenuiflorum $+C$. indica i.e $(\mathrm{p}<0.05)$.

In MRSA isolate no. 5 no any effect, were seen in synergistic plant extracts i.e., $O$. tenuiflorum $+A$. indica, $O$. tenuiflorum $+C$. indica, $O$. tenuiflorum $+A$. vulgaris and $A$. indica $+A$. vulgaris of all volumes. In $C$. indica $+A$. vulgaris and $C$. indica $+A$. indica zone of inhibition were seen only at $100 \mu \mathrm{L}$ volume (13mm and $14 \mathrm{~mm}$ respectively).

The zone of clearance was same $(p>0.05)$ for $O$. tenuiflorum $+A$. indica, $C$. indica $+A$. vulgaris, $O$. tenuiflorum $+C$. indica, $C$. indica $+A$. indica and $A$. vulgaris $+A$. indica and the zone of clearance was significantly different for $C$. indica $+A$. indica $(\mathrm{p}<0.05)$.

In the study, four plants methanolic extract were used for the antibacterial activity. The antibacterial effect of leafs extract in combination showed that extracts were effective against MRSA isolates at different volumes. The combination of plant extracts with Castanopsis indica showed greater antibacterial activity in 
comparison to other combined plant extract in all volume (figure 2).
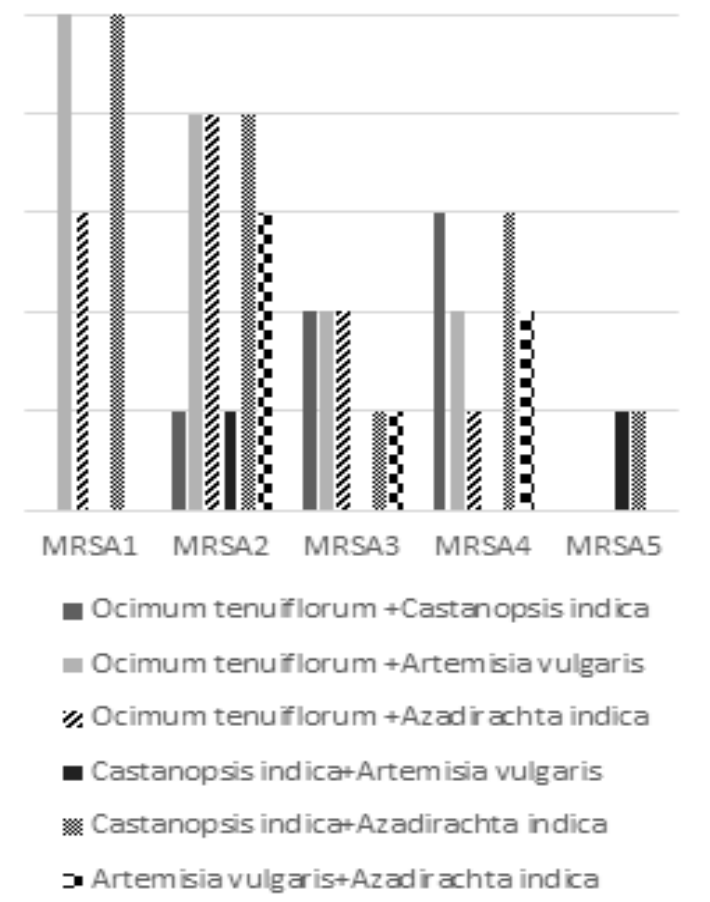

Figure 2: Maximum zone of inhibition shown by plant extract in combination against different MRSA isolates.

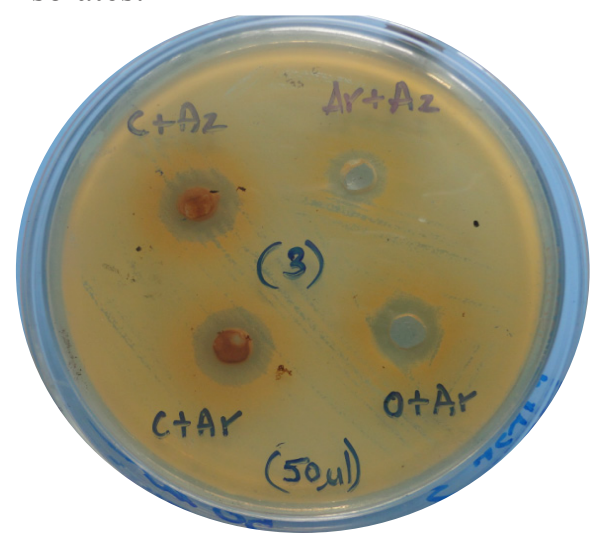

Figure 3: Synergistic effect of four leaf extracts against isolate no. 3 in $50 \mu \mathrm{L}$ volume.

\section{DISCUSSION}

Staphylococcus aureus is an opportunistic pathogen often carried asymptomatically on the human body. Methicillin-resistant $S$. aureus (MRSA) include those strains that have acquired a gene giving them resistance to methicillin and essentially all other beta-lactam antibiotic (CFSPH 2011).

The use of herbal preparations made from medicinal plants is widespread in developing countries. The healing powers of traditional herbal medicines have been realized and about $65 \%$ of the world populations have access to local medicinal plant knowledge system. The need for new and useful compounds is evergrowing (Sidkey et al 2014).

In the present study, methanol leaf extracts of four medicinal plants- Azadirachta indica, Artemisia vulgaris, Castanopsis indica and Ocimum tenuiflorum against five MRSA isolates were studied in five different concentrations. Methanol extracts of four plants giving six synergistic combinations have been observed. The study shows that the methanol extracts of each plant which exhibits antibacterial activity against all tested MRSA isolates at all concentration and the results were acceptable.

Result analysis was done through two way ANOVA test were single antibacterial activity of all extracts has been studied against each MRSA isolates individually. ANOVA test enables to study the mean antibacterial activity of all leafs extracts at different concentrations.

Among the five concentrations $(1 \mu \mathrm{L}, 25 \mu \mathrm{L}$, $50 \mu \mathrm{L}, 75 \mu \mathrm{L}$ and $100 \mu \mathrm{L})$ used, maximum inhibitory zone was observed at $100 \mu \mathrm{L}$, followed by $75 \mu \mathrm{L}, 50 \mu \mathrm{L}, 25 \mu \mathrm{L}$ and $1 \mu \mathrm{L}$. This study frames that as the concentration of the extract increases, the zone of inhibition also increases.

In synergistic effect the highest antimicrobial activity was observed in Castanopsis indica+Azadirachta indica, followed by Ocimum tenuiflorum + Artemisia vulgaris and 
Ocimum tenuiflorum + Azadirachta indica.

Castanopsis leaf extracts contains ingredients which block the virulence and pathogenesis of $S$. aureus and it has been found that broadspectrum activity against the skin microflora also holds the potential for fostering an environment amenable to the proliferation of pathogenic bacteria (Quave et al, 2015).

According to Sharma et al(2012) the antibacterial activity in Ocimum tenuiflorum may be due to the presence of several metabolites like alkaloids, tannins and sterols and the hydroxyl group on phenol components may increase in toxicity against the microorganisms.

Javid et al (2015) stated that Artemisia vulgaris possess good antibacterial activity against $S$. aureus. The antimicrobial activity of the tested extracts and fractions are comparable with the standard drugs. These activities may be due to strong occurrence of different chemical compounds such as flavonoids, tannins, alkaloids, steroids, phenols and saponins.

\section{ACKNOWLEDGEMENTS}

We would like to acknowledge Mr. Hari Prasad Khanal, Campus Chief of Pokhara Bigyan Tatha Prabidhi Campus, Nayabazar for his kind organizational support to us for research.

\section{REFERENCES}

Abd El-Kalek HH and AE Mohamed (2012). Synergistic effect of certain medicinal plants and amoxicillin against some clinical isolates of methicillin-resistant Staphylococcus aureus (MRSA). International Journal of Pharmaceutical Applications 3:387-398.

Al-Ali K, M. Abdelrazik, H. Hemeg and H. Ozbak (2014). Antibacterial activity of four herbal extracts against methicillin resistant Staphylococcus aureus strains isolated from patients in Almadinah hospital, Saudi Arabia. International Journal of Academic
Scientific Research 2:27-343.

Ashok, P.K. and K. Upadhyaya (2010). Preliminary phytochemical screening and physico-chemical parameters of aerial parts of Artemisia vulgaris. International Journal of Research in Ayurveda and Pharmacy 1:206-211.

Barney N.J. and A. Di Tommaso (2003). The biology of Canadian weeds. Artemisia vulgaris L. Canadian Journal of Plant Science 83:205-215.

Bhatt K.M., B.M. Shankar, K.A. Saluja, K.K. Dholwani and A.D. Captain (2012). Evaluation of antibacterial activity of Ocimum sanctum Methanolic extract. Journal of Pharmaceutical and Scientific Innovation 1:39-41.

Center for Food Security and Public Health (CFSPH) (2011). Methicillin-resistant Staphylococcus aureus. Available at: http:// www.cfsph.iastate.edu/Factsheets/pdfs/ mrsacitations.pdf

Dolai N, I. Karmakar, S.R.B. Kumar, B. Kar, A. Bala and K.P. Haldar (2012). Free radical scavenging activity of Castanopsis indica in mediating hepato protective activity of carbon tetrachloride intoxicated rats. Asian Pacific Journal of Tropical Biomedicine. S242-S251.

Erel B.S., G. Reznicek and G.S. Senol (2012). Antimicrobial and antioxidant properties of Artemisia L. species from western Anatolian. Turk J Biol 36:75-84.

Geetha R.V. and A. Roy (2013). In vitro evaluation of antibacterial activity three herbal extracts on methicillin resistant Staphylococcus aureus [MRSA]. Journal of pharmaceutical sciences and research 5:207-209.

Gupta B, Kumar VN and Mallaiah S (2013). Assessment of antimicrobial activity of 
various concentrations of commercially available Tulsi (Ocimum sanctum) powder against Streptococcus mutans. Open Journal of Dentistry and Oral Medicine 1:19-24.

Javid T., M. Adnan, A. Tariq, B. Akhtar, R. Ullah and M.N. Abde (2015). Antimicrobial activity of three medicinal plants (Artemisia indica, Medicago falcate and Tecoma stans). Afr.J Tradit Company Altern Med 12:91-96.

Joshi R.J. and P.S. Devkota (2014). Methicillin resistant Staphylococcus aureus (MRSA) in cattle: epidemiology and zoonotic implications. Int J Appl Sci Biotechnol 2:29-33.

Kayastha B.B., S. Manandhar and B. Shrestha (2010). Methicillin resistant Staphylococcus aureus (MRSA) in different clinical sample from patients presenting at Kathmandu Model Hospital. Research gate. Available at: http://www.researchgate.net/ publication $/ 216834367$

Maragathavalli S., S. Brindha, N.S.B. Kaviyarasi, B. Annadurali and S.K. Gangwar (2012). Antimicrobial activity in leaf extract of neem (Azadirachtaindica Linn.). International Journal of Science and Nature 3:110-113.

Quave L.C., T.J. Lyles, S.J. K. Kavanaugh, Nelson, P.C. Parlet, A.H. Crosby, P.K. Heilmann and R.A. Horswill (2015). Castanea sativa (European Chestnut) Leaf extracts rich in Ursene and Oleanene derivatives block Staphylococcus aureus virulence and pathogenesis without detectable Resistance PLos ONE 10:1-32.

Rathnayaka R.M. (2013). Antimicrobial activity of Ocimum sanctum extracts against four food-borne microbial pathogens. Sch J App Med Sci1:774-777.

Sanjana K.R., R. Shah, N. Chaudhary and I.Y. Singh (2010). Prevalence and antimicrobial susceptibility pattern of methicillin-resistant Staphylococcus aureus (MRSA) in CMSteaching hospital: a preliminary report. Journal of College of Medical SciencesNepal 6:1-6.

Sidkey, Nagwa M, Aytah, A .Ameera, Al-Ahmadi and A. Hind (2014). Antimicrobial Activity of Costus Plant Extract Against MethicillinResistant Staphylococcus aureus (MRSA, I3). An International Journal of Science and Research 4:348-359.

Sharma A., A. Meena and R. Meena (2012). Antimicrobial activity of plant extracts of Ocimum tenuiflorum. IJPRIF 4:176-180.

Zivkovic J, I. Mujic, Z. Zekovic, S. Vidovic, A. Mujic and S. Jokic (2009). Radical scavenging, antimicrobial activity and phenolic content of Castanea sativa extracts. Journal of Central European Agriculture 10:175-182.

(Received 8 June 2017, revised accepted 11 Aug 2017) 